\title{
Impact of e - Velanmai Model of Extension Service in Tamil Nadu
}

\author{
D. Prabha ${ }^{1 *}$, Ravi Kumar Theodore ${ }^{2}$ and C. Karthikeyan ${ }^{3}$ \\ 183(Agrl. Extension), Tamil Nadu Agricultural University, Coimbatore - 03 \\ ${ }^{2}$ (Agrl. Extension), Tamil Nadu Rice Research Institute, Aduthurai - 01
}

\begin{abstract}
"e-Velanmai" in a coordination of personal and ICT based agricultural extension approach implemented in Tamil Nadu to provide need based and timely advisories to farmers. An impact study of e-Velanmai model of extension, implemented by Tamil Nadu Agricultural University, was undertaken in three districts viz., Coimbatore, Tirupur and Villupuram of Tamil Nadu with 90 beneficiary respondents and 90 non-beneficiary respondents. Research reveal that the beneficiary respondents were significantly higher in their extent of adoption of recommended technologies than that of the non-beneficiary respondents. Majority of the respondents had expressed medium level of social impact. Increasing the number of field coordinators, proving information on dayto-day market details and providing information on post harvest technology and value addition of coconut and other crops were the suggestions offered by the beneficiaries for improving the e-Velanmai services.
\end{abstract}

Key words: e-Velanmai, ICT, Adoption, Impact, Suggestions

"e-Velanmai" means 'Electronic Agriculture'. It is a World Bank sponsored project which was operated by the Tamil Nadu Agricultural University (TNAU) from July 2007 to March 2013. According to Karthikeyan (2012) e-Velanmai is a combination of personal and ICT based, demand driven and participatory technology transfer model in agriculture to provide timely agro advisory services by a multidisciplinary team of agricultural scientists to farmers using ICT tools (Digital Camera, Computer, Internet, Mobile Phone, etc.) through a Field Coordinator (FC) on need basis. It is a sustainable approach of technology transfer for enabling scientific farming and thereby enhancing farm productivity.

As e-Velanmai was a paid model of extension service and a new venture, it was expected that it would evoke different kinds of responses from among the beneficiaries. Totally, 10,507 farmers, of which 1,076 were farm women, were enrolled as members in the project by paying a annual nominal fee of Rs. 50/- per farmer with upto five acres of land, Rs. 100/for those with 5.1 to 10 acres, and Rs. 150/- for those with land holding of above 10 acres. During the project period, based on demand advices were given to the members to solve their farm problems and to take informed decisions.

Further, in each of the member's family, at least one person was trained in handling the ICT tools for the purpose of framing the crop status images and to access the advice from experts. It was envisioned that the trained individuals were expected to capture and send the digital images of the pest damaged

*1Corresponding author email: mahaprabha014@gmail.com symptoms or disease symptoms and receive technical advice from TNAU experts.

The objectives of the study were as follows:

a. To assess the impact of e-Velanmai model of extension among the beneficiaries.

b. To elicit suggestions from the beneficiaries for further improving the e-Velanmai model of extension.

\section{Material and Methods}

The e-Velanmai project was implemented in three districts of Tamil Nadu viz., Coimbatore (Aliyar sub-basin), Tirupur (Palar sub-basin) and Villupuram (Varahanadhi sub-basin), and therefore the study was carried out in all these three districts. The respondents of the study were registered members (beneficiaries) of e-Velanmai. Based on probability proportionate sampling method, 30 beneficiary respondents were selected from two Water User Associations (WUAs) in Aliyar sub-basin; 30 respondents from three WUAs in Palar sub-basin; and 30 respondents from three WUAs in Varahanadhi sun-basin, and thus the total sample size of the beneficiaries was 90 .

The impact was assessed by means of the outcome observed namely, Extent of Adoption and Social Impact.

'Extent of Adoption' was operationalized as the level of adoption of recommended agricultural technologies by the beneficiary (under e-Velanmai) and non-beneficiary respondents. Extent of Adoption was measured in teams of 'Technology-wise Adoption. 
The 'Technology-wise Adoption' was measured by means of an Adoption Index followed by Godhandapani (1985) and Theodore (1988), which is given as follows:

$$
\text { Technology-wise Adoption }=\frac{\text { Actual }}{\text { Recommended }}
$$

For this purpose, with respect to beneficiaries the problems encountered by the respondents that were recorded in the membership card were taken into account. The extent of adoption was worked out for each of the technologies recommended by the TNAU Scientists for the problems reported by the respondents. The Technology-wise Adoption values were summed up and then finally divided by the number of technologies recommended. The resulting value was multiplied by 100 to indicate the Technologywise Adoption value in terms of percentage. Lower percentage indicated 'less adoption' and higher percentage meant 'high adoption'. Based on the percentages, the respondents were classified into low, medium and high categories using frequency distribution method. In the case of non-beneficiaries, the major package of practices followed for the crops grown by them were considered for assessing their adoption. The rest of the procedure as followed for beneficiaries was followed for non-beneficiaries also.

Social Impact was operationalized as a measure of the social changes that occurred in the life of the beneficiaries due to their participation in the e-Velanmai model of extension. Social Impact was measured by means of a schedule developed for the study. The tool comprised of six statements that covered different dimensions of social change that are likely to have occurred in the life of the beneficiaries due to their participation e-Velanmai.

\section{Results and Discussion}

\section{Extent of adoption}

It is seen from Table 1 that all the beneficiary respondents were found with high level of extent of adoption. Among non-beneficiary respondents, it was found that more than three-fourths $(87.78 \%)$ had high level of extent of adoption and the rest (12.22\%) had low level of extent of adoption. This finding is in conformity with that of Shanthinichandra (2012) who had observed in her study on formative evaluation of e-Velanmai model of agricultural extension that almost all the beneficiary respondents of e-Velanmai $(97.50 \%)$ had adopted the recommendations given by the TNAU scientists for the problem-based queries.

Table 1. Distribution of respondents according to extent of adoption

\begin{tabular}{lcccc}
\hline \multirow{2}{*}{ Extent of adoption categories } & \multicolumn{2}{c}{ Beneficiaries } & \multicolumn{2}{c}{ Non-beneficiaries } \\
\cline { 2 - 5 } & No. $(\mathrm{n}=90)$ & Per cent & No. $(\mathrm{n}=90)$ & Per cent \\
\hline Low $(1-33 \%)$ & 0 & - & 11 & 12.22 \\
Medium $(34-66 \%)$ & 0 & - & 0 & - \\
High $(67-100 \%)$ & 90 & 100 & 79 & 100.00 \\
Total & 90 & 100.00 & 90 & \\
Mean & 100.00 & 92.41 & & \\
Difference between means & 7.59 & & & \\
't' value & $3.335^{* *}$ & & & \\
C.V \% & 9.26 & 34.24 & & \\
\hline
\end{tabular}

**Significant at 0.01 level of probability

Since, the 't' value was significant at 0.01 level, the null hypothesis is rejected, indicating that there existed a significant difference between beneficiary and non-beneficiary respondents with respect to their extent of adoption. The C.V. was 9.26 per cent for beneficiary respondents, while it was 34.24 per cent for non-beneficiary respondents, indicating that the internal variation of non-beneficiary respondents was higher than that of the beneficiaries with respect to extent of adoption.

\section{Social impact}

Table 2 indicates that nearly three-fourths (73.40 $\%$ ) of the beneficiary respondents had medium level of social impact, followed by 23.30 per cent with high level of social impact, and the rest $(3.30 \%)$ had low level of social impact.
The Coefficient of Variation was found to be 0.89 per cent, which indicates that there existed a very high level of internal consistency among the beneficiary respondents with respect to social impact variable.

Table 2. Distribution of respondents according to social impact

\begin{tabular}{lcc}
\hline \multirow{2}{*}{$\begin{array}{l}\text { Social impact } \\
\text { categories }\end{array}$} & \multicolumn{2}{c}{ Beneficiaries } \\
\cline { 2 - 3 } Low (6- 7 scores) & No. $(\mathrm{n}=90)$ & Per cent \\
Medium (8- 9 scores) & 66 & 3.30 \\
High (10-12 scores) & 21 & 73.40 \\
Total & 90 & 23.30 \\
C.V \% & 0.89 & \\
\hline
\end{tabular}


Majority of the respondents had expressed medium level of social impact. It was reported earlier that the awareness on e-Velanmai model of extension was low for most of the non-beneficiary respondents. This means that, though e-Velanmai was much preferred by the beneficiaries, it was still unknown to others in the same area. This may be the reason for the observed results.

\section{Correlation of independent variables with technology-wise adoption}

Correlation analysis was carried out between the independent variables with technology-wise adoption and social impact. The results are presented as follows:

Table 3 shows the results of the correlation between 12 profile characteristics of beneficiary respondents and non-beneficiary respondents with technologywise adoption. Out of the 12 profile characteristics of beneficiary respondents, four characteristics viz., age, farm size, contact with extension and other agencies and exposure to agricultural messages had positive and significant association with adoption. In the case of non-beneficiary respondents, out of the 12 profile characteristics, four characteristics viz., farm size, social participation, contact with extension and other agencies and exposure to agricultural messages had positive and significant relationship with technologywise adoption.

Table 3. Correlation of independent variables with technology-wise adoption

\begin{tabular}{lcc}
\hline \multirow{2}{*}{ Independent variables } & $\begin{array}{c}\text { Beneficiaries } \\
(\mathrm{n}=90)\end{array}$ & $\begin{array}{c}\text { Non- } \\
\text { beneficiaries } \\
(\mathrm{n}=90)\end{array}$ \\
\cline { 2 - 3 } & $0.218^{*}$ & $-0.156 \mathrm{NS}$ \\
Age & $-0.005 \mathrm{NS}$ & $0.059 \mathrm{NS}$ \\
Occupational Status & $0.135 \mathrm{NS}$ & $0.031 \mathrm{NS}$ \\
Farm Size & $0.225^{*}$ & $0.256^{*}$ \\
Farming Experience & $0.93 \mathrm{NS}$ & $0.023 \mathrm{NS}$ \\
Annual Income & $0.091 \mathrm{NS}$ & $0.040 \mathrm{NS}$ \\
Social Participation & $0.018 \mathrm{NS}$ & $0.340^{* *}$ \\
Contact with Extension and & $0.271^{* *}$ & $0.554^{* *}$ \\
other Agencies & & \\
Exposure to Agricultural & $0.219^{*}$ & $0.253^{*}$ \\
Messages & & \\
Innovativeness & $-0.161 \mathrm{NS}$ & $0.029 \mathrm{NS}$ \\
Risk Orientation & $0.125 \mathrm{NS}$ & $0.162 \mathrm{NS}$ \\
Scientific Orientation & $0.049 \mathrm{NS}$ & $0.194 \mathrm{NS}$ \\
\hline ** Significant at 0.01 level of probability & \\
* Significant at 0.05 level of probability & & \\
NS = Non-Significant & & \\
\hline
\end{tabular}

The correlation values of contact with extension and other agencies was significant at 0.01 per cent level and age, farm size and exposure to agricultural messages were significant at 0.05 per cent level. As far as non-beneficiary respondents were concerned, the correlation values of social participation and contact with extension and other agencies were significant at 0.01 per cent level while farm size and exposure to agricultural messages were significant at 0.05 per cent level.

Rejecting and accepting the null hypotheses for significant and non-significant correlation values respectively, it is inferred that the technology-wise adoption of beneficiary respondents was the function of their age, farm size, contact with extension and other agencies and exposure to agricultural messages, while it was the function of farm size, social participation, contact with extension and other agencies and exposure to agricultural messages in the case of non-beneficiary respondents.

Table 4. Correlation of independent variables with social impact

\begin{tabular}{|c|c|}
\hline Independent variables & $\begin{array}{l}\text { Beneficiary respondents } \\
\qquad(n=90)^{\prime} r \text { ' value }\end{array}$ \\
\hline Age & $-0.127 N S$ \\
\hline Educational Status & $-0.009 N S$ \\
\hline Occupational Status & $0.168 \mathrm{NS}$ \\
\hline Farm Size & $-0.129 N S$ \\
\hline Farming Experience & $-0.052 N S$ \\
\hline Annual Income & $0.016 \mathrm{NS}$ \\
\hline Social Participation & $0.188 \mathrm{NS}$ \\
\hline $\begin{array}{l}\text { Contact with Extension and } \\
\text { other Agencies }\end{array}$ & $0.450^{* *}$ \\
\hline $\begin{array}{l}\text { Exposure to Agricultural } \\
\text { Messages }\end{array}$ & $0.238^{*}$ \\
\hline Innovativeness & $0.628^{*}$ \\
\hline Risk Orientation & $-0.448^{* *}$ \\
\hline Scientific Orientation & $-0.258^{*}$ \\
\hline \multicolumn{2}{|l|}{ ** Significant at 0.01 level of probability; } \\
\hline \multicolumn{2}{|l|}{ *Significant at 0.05 level of probability } \\
\hline \multicolumn{2}{|l|}{$N S=$ No } \\
\hline \multicolumn{2}{|c|}{$\begin{array}{l}\text { Thus, it is concluded that higher the age, farm } \\
\text { size, contact with extension and other agencies and } \\
\text { exposure to agricultural messages, irrespective of } \\
\text { their educational status, occupational status, farming } \\
\text { experience, annual income, social participation, } \\
\text { innovativeness, risk orientation and scientific } \\
\text { orientation, higher will be the technology-wise } \\
\text { adoption of beneficiary respondents. With regard } \\
\text { to non-beneficiary respondents, higher their farm } \\
\text { size, social participation, contact with extension } \\
\text { and other agencies and exposure to agricultural } \\
\text { messages, irrespective of their age, educational } \\
\text { status, occupational status, farming experience, } \\
\text { annual income, innovativeness, risk orientation and } \\
\text { scientific orientation, higher will be their technology- } \\
\text { wise adoption level. }\end{array}$} \\
\hline
\end{tabular}




\section{Correlation of independent variables with social impact}

Table 4 shows the correlation between 12 profile characteristics of beneficiary respondent with social impact. Out of the 12 profile characteristics of beneficiary respondents, five characteristics viz., contact with extension and other agencies, exposure to agricultural messages, innovativeness, risk orientation and scientific orientation showed significant relationship with social impact.

Table 5. Distribution of beneficiary respondents according to their suggestions for improving the services under e-Velanmai

\begin{tabular}{lcc}
\hline \multicolumn{1}{c}{ Suggestions } & \multicolumn{2}{c}{ Beneficiaries } \\
\cline { 2 - 3 } & $\begin{array}{c}\text { No. } \\
(\mathrm{n}=90)\end{array}$ & $\begin{array}{c}\text { Per } \\
\text { cent }^{*}\end{array}$ \\
\hline $\begin{array}{l}\text { Number of Field Coordinators may be } \\
\text { increased }\end{array}$ & 78 & 86.60 \\
$\begin{array}{l}\text { Day-to-day Market Information may be } \\
\text { provided }\end{array}$ & 65 & 72.20 \\
$\begin{array}{l}\text { Post Harvest Technology/ Value Addition } \\
\text { information for coconut and other crops }\end{array}$ & 45 & 50.00 \\
may be provided & & \\
$\begin{array}{l}\text { A separate office for e-Velanmai project may } \\
\text { be opened in every sub-basin }\end{array}$ & 43 & 47.70 \\
$\begin{array}{l}\text { Schemes with Subsidy details may be } \\
\text { provided }\end{array}$ & 19 & 21.10 \\
$\begin{array}{l}\text { Farm Machinery details for various crops } \\
\text { may be provided }\end{array}$ & 18 & 20.00 \\
$\begin{array}{l}\text { TNAU Scientists need to visit farmers fields } \\
\text { once a month, as part of the e-Velanmai } \\
\text { project }\end{array}$ & 7 & 7.70 \\
\hline
\end{tabular}

* Multiple Reponses.

The correlation value of contact with extension and other agencies and risk orientation were significant at 0.01 per cent level. Contact with extension and other agencies was positively correlated while risk orientation was negatively correlated. The variables viz., exposure to agricultural messages, innovativeness and scientific orientation showed significant relationship at 0.05 per cent level. Exposure to agricultural messages and innovativeness were positively correlated, while scientific orientation was negatively correlated.

Rejecting and accepting the null hypotheses for significant and non-significant correlation values respectively, it is inferred that the social impact was the function of contact with extension and other agencies, exposure to agricultural messages, innovativeness, risk orientation and scientific orientation.

Thus, it is concluded that higher the contact with extension and other agencies, exposure to agricultural messages and innovativeness and lower the risk orientation and scientific orientation of beneficiary respondents, higher will be their social impact, irrespective of their age, educational status, occupational status, farm size, farming experience, annual income and social participation.

\section{Suggestions given by beneficiaries for improving the} services under e- Velanmai

It is observed from Table 5 that the foremost reason expressed by the beneficiary respondents was "Number of Field Coordinators may be increased" ( $86.60 \%)$, followed by "Day-to-day market information may be provided" (72.20 \%),

"Post Harvest Technology / Value Addition information for coconut and other crops may be provided" (50.00\%), "A separate office for e-Velanmai project may be opened in every sub-basin" (47.70 $\%)$, "Schemes with Subsidy details may be provided" (21.10\%), "Farm Machinery details for various crops may be provided" (20.00\%) and "TNAU Scientists need to visit farmers fields once a month as part of the e-Velanmai project" $(7.70 \%)$.

\section{Conclusion}

High adoption level was found with cent per cent of the beneficiaries of e-Velanmai model of extension, which is highly favorable. The ultimate aim of any extension effort mostly is to increase the adoption level of recommended technologies by farmers, which seems to have been adequately fulfilled by the e-Velanmai project. The correlation analysis revealed that there existed a positive and significant association between the dependent variable parameters viz., Extent of adoption and Social impact. This finding reinforces the efficiency with which the services have been offered under e-Velanmai to its members. These findings not only empirically prove the effectiveness of e-Velanmai beyond doubt, but also indicate the potential of e-Velanmai model of extension to supplement and complement the existing extension activities of the State Department of Agriculture.

\section{References}

Karthikeyan, C. 2012. "e-Velanmai- An ICT Enabled Agricultural Extension Model". International Journal of Extension Education, 8: 24-30.

Godhandapani, G. 1985. Knowledge and Adoption of Nutrient Recommendation for Irrigated Groundnut. Unpub. M.Sc. (Ag.) Thesis, TNAU, Coimbatore

Shanthinichandra, S. 2012. Formative Evaluation of e-Velanmai Model of Agricultural Extension. Pub. M.Sc. (Ag.) Thesis, TNAU, Coimbatore. p: 54 - 56.

Theodore, Ravi Kumar. 1988. Awareness, Conviction and Adoption of Technological units of Contingency Farming Practices for Rice by Contact and other Farmers of Thanjavur District, Unpub. M.Sc. (Ag.) Thesis, TNAU, Coimbatore. p: $69-73$. 